\title{
The Effects of Magnetic Field on TLD Glow Curve
}

\author{
Jaeyong Je, Eunbo kang \\ Department of Radiological Technology, Dong-Eui Institute of Technology \\ 자기장이 열형광선량계의 글로우 곡선에 미치는 영향 \\ 제재용, 강은보 \\ 동의과학대학교 방사선과
}

\begin{abstract}
Thermoluminescent dosimeter utilizes the fact that when irradiated specimen is heated up, some part of the absorbed energy is emitted from the specimen as light with longer wavelength. This research aims at analyzing the glow curves of four TLD-100 exposed to a magnetic field and those of other four TLD-100 not exposed to one by treating them with heat and irradiating them, which are commonly used as thermoluminescent dosimeter, in the same condition. As the result of the experiment, regarding the electrons captured by irradiation, some of the electrons of lower traps were combined with positive holes of valence .band through the exposure to a magnetic field, and the peak size decreased by $48 \%$. The reduction in the size of the lower traps caused the TLD-100 exposed to a magnetic field to display a low level of dose. In addition, low traps estimated activation energies are $1.6 \mathrm{eV}$ and $1.5 \mathrm{eV}$.
\end{abstract}

Key Words: magnetic field, radiation, TLD, exposure dose, trap, activation energy

\section{요 야}

방사선을 조사한 시료를 가열하면 시료로부터 흡수된 에너지의 일부가 더 긴 파장의 빛으로 방출되는 것을 이용한 것이 열형광선량계이다. 본 연구의 목적은 피폭선량계로 널리 이용되는 8개의 TLD-100에 동일한 조건에서 열처리와 방사선을 조사하여 자기장을 노출하지 않은 4 개와 자기장에 노출시킨 4 개를 글로우 곡선을 분석 하였다. 실험 결과 방사선 조사로 포획된 전자가 자기장 노출에 의해 낮은 트랩의 전자들 중 일부는 가전자대의 정공과 결합하여 $48 \%$ 의 피크 면적이 감소하였다. 낮은 트랩의 면적 감소로 인하여 자기장에 노출된 TLD-100은 낮은 선량을 나타내었다. 또 한 낮은 트랩의 활성화 에너지는 $1.6 \mathrm{eV}$ 와 $1.5 \mathrm{eV}$ 로 나타났다.

중심단어: 자기장, 방사선, 열형광선량계, 피폭선량, 포획, 활성화 에너지

\section{I. 서 론}

방사선을 취급하는 원자력 발전소와 산업체 및 의 료기관에 종사하는 방사선 작업종사자는 개인피폭선
량계로서 대부분 열형광선량계(TLD)를 사용하고 있다. 열형광은 오래전부터 알려저 왔으나 Becqurell이나 Wiedemann ${ }^{[1]}$ 등에 의하여 19 세기 중반부터 구체적으로 연구되었고 20세기에 이르러 Randall 과 Willkins ${ }^{[2]}$ 등의 
의해 이론적으로 설명이 가능해졌다. TLD는 방사선에 대한 감도와 안정성이 높은 것으로 알려져 있어 방사 선 선량측정과 개인피폭선량계로 널리 이용된다. 이러 한 $\mathrm{TLD}$ 는 비교적 동작원리가 간단하고 장기간에 걸 친 집적선량이 선형적인 장점을 가지고 있다 ${ }^{[3]-[5]}$. 기 존 TLD의 연구들은 열형광 강도를 증가시키기 위하 여 활성제 첨가와 열처리 방법 등에 국한되어졌다. 방 사선을 이용한 진단 영역의 확대와 더불어 핵의학에 서 많은 발전을 가져왔으며, 이러한 핵의학의 발전은 국내에서도 PET-MRI가 설치되어 운영되어지고 있다. 그러나 PET-MRI가 개발되기 전까지는 개인피폭선량 계인 TLD가 자기장에 노출되지 않았으나 PET-MRI의 개발과 운영으로 인하여 자기장과 방사선에 함께 노 출이 된다. 최근 연구에서 이러한 자기장 노출은 TLD 의 판독에서 개인피폭선량 오차를 발생시키는 것으로 나타났으며, 본 연구에서는 $\mathrm{LiF}$ 를 모체로 하는 TLD-100 결정에 방사선 조사 후 자기장 노출 유무에 따른 글로우 곡선을 분석하고자 하고자 한다.

\section{II. 대상 및 방법}

\section{1 연구대상}

본 연구에서 사용한 TLD-100의 구성물질은 $\mathrm{LiF}: \mathrm{Mg}, \mathrm{Ti}$ 이고 TLD-100의 자기장 노출 유무에 따른 글로우 곡선의 포획 매개 변수 결정방법은 peak shape 법을 이용하였다. 그리고 글로우 곡선의 대칭성을 이 용하여 아래의 식으로부터 활성화 에너지를 구하였다.

$$
E=q k T_{m}^{2} / \delta
$$

$T_{m}$ 은 최고 peak 지점의 온도, $\mathrm{q}$ 는 글로우 곡선의 모양에서 계산되는 인자이다. Halperin과 Braner ${ }^{[6]}$, Grossweiner $^{[7]}$ 및 Lushchik ${ }^{[8]}$ 등은 매개변수를 사용하여 1 차 및 2 차 발광과정에 대해 활성화 에너지를 결정하 는 방법을 제시하였다. 발광과정이 1 차 및 2 차일 때 각 각의 인자 $\mathrm{q} 1$ 과 $\mathrm{q} 2$ 는 다음과 같이 나타낼 수 있다.

$$
\begin{aligned}
& \mathrm{q}_{1}=1.72 \frac{\mu_{\mathrm{g}}}{1-\mu_{\mathrm{g}}}(1-1.58 \mathrm{C}) \\
& \mathrm{q}_{2}=\frac{2 \mu_{\mathrm{g}}}{1-\mu_{\mathrm{g}}}(1-2 \mathrm{C}) \ldots \ldots \ldots \ldots \ldots \ldots \ldots \ldots \ldots \ldots
\end{aligned}
$$

$\mu_{g}$ 는 glow curve의 기하학적 인자로서 $\mu_{g \leq e^{-1}(1+C)}$ 일 때는 1차 발광이고 $\mu_{g>e^{-1}(1+C)}$ 이면 2차 발광이다. $\mathrm{C}=\frac{2 \mathrm{kT}_{\mathrm{m}}}{\mathrm{E}}$ 이며, $\mu_{\mathrm{g}}$ 에 대한 근사식은 $\mu_{\mathrm{g}}^{\prime}=\frac{\delta}{\omega}$ 이다.

Fig. 1 의 단일 글로우 곡선의 peak 온도를 $T_{m}$, peak 강도의 $1 / 2$ 이 되는 저온쪽 온도를 $\mathrm{T}_{1}$, 고온측 온도를 $\mathrm{T}_{2}$, peak의 반치폭을 $\omega=T_{2}-T_{1}, \delta=T_{2}-T_{m}$ 라 하고 $\mu_{g}=\delta / \omega$ 라 할 때 발광차수에 대한 활성화 에 너지 $\mathrm{E}$ 는

$$
E=\left[2.52+10.2\left(\mu_{g}-0.42\right)\right] \frac{k T_{m}^{2}}{\omega}-2 k T_{m} \ldots \ldots \ldots . .(4)
$$

와 같이 구할 수 있다.

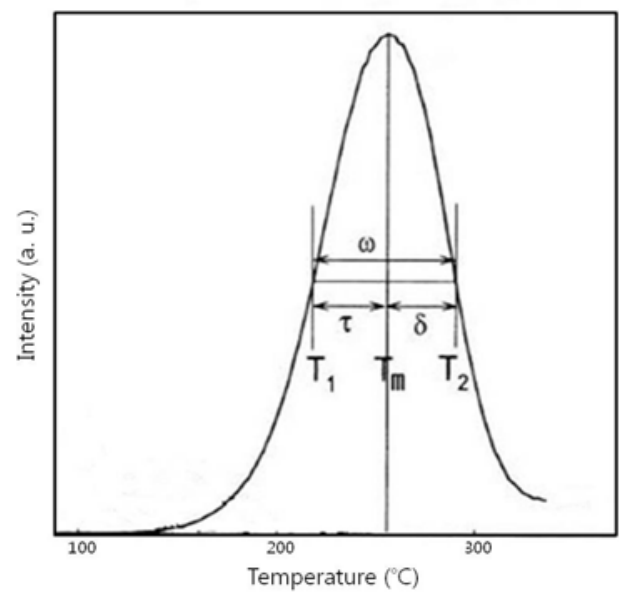

Fig. 1. Typical Isolated Glow Curve with the Parameters.

\section{2 실험방법}

PET-MRI는 PET장치에 3 Tesla 자기장의 MRI 의료 장비가 결합되어 있는 구조로서 가우스메타(TM-701, Kanetec, Japan)를 이용하여 방사선 작업 종사자가 위치 하는 곳의 자기장 세기를 측정하였다. 본 실험에서는 $\mathrm{MRI}$ 장치를 대신하여 방사선 작업종사자가 노출되는 자기장의 세기와 비슷한 세기를 나타내는 네오디움 자석을 이용하였다. 실험에 사용한 TLD chip의 물질은 TLD-100으로서 구성성분은 $\mathrm{LiF}: \mathrm{Mg}, \mathrm{Ti}$ 이고 크기는 $3.175 \times 3.175 \times 0.889 \mathrm{~mm}$ 이다. 포획된 전자를 제거하기 위하여 전기로(아전가열, Korea)를 사용하였고, $100^{\circ} \mathrm{C}$ 에서 1 시간, $300^{\circ} \mathrm{C}$ 에서 2 시간 동안 소성(annealing)하였 
다. 열처리한 TLD chip은 진단용 방사선 발생장치 (BLD-150RK, Listem, Korea)를 이용하여 $100 \mathrm{kVp}, 320$ $\mathrm{mAs}$ 를 조사하였다. 방사선이 조사된 chip은 24시간 후 TLD Reader(Hashaw 3500, Thermo Fisher Scientific, $\mathrm{USA}$ 를 이용하여 선량과 글로우 곡선을 측정하였다. 측정 조건은 $15{ }^{\circ} \mathrm{C} / \mathrm{sec}$ 의 가온율로 $50 \sim 260^{\circ} \mathrm{C}$ 까지 측정 하여 글로우 곡선을 획득하였다.

실험에 사용한 TLD chip은 동일한 환경에서 100 개 의 TLD chip을 소성하여 방사선 조사 후 특성이 0.99 $\sim 0.01 \%$ 의 오차를 나타내고 글로우 곡선의 형태와 주 peak를 나타내는 곡선의 위치가 거의 동일한 8 개를 선 택하여 사용하였다. 8개의 TLD chip 중 4개는 Fig. 2 의 네오디움 자석(a)와 (b) 사이에서 24시간 자기장에 노출 시키고 나머지 4개는 암실에 보관하였다. 네오디 움 자석의 크기는 $50 \times 50 \times 15 \mathrm{~mm}$ 이고, 자석의 중심부 자기장 세기는 가우스메타를 이용하여 측정하였다.

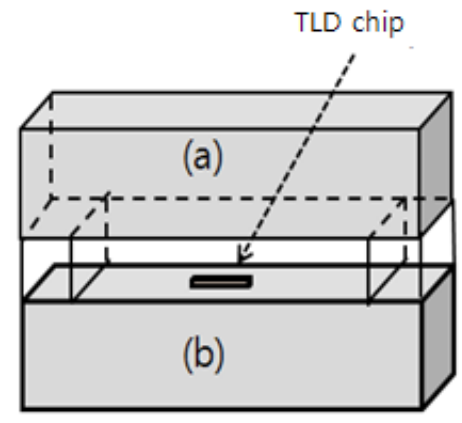

Fig. 2. Schematic of Magnetic Exposure.

\section{III. 결 과}

가우스 메타를 이용하여 3Tesla MRI 장비의 외부 자 기장 세기는 약 5000 Gauss 정도를 나타내었으며, 실험 에 사용한 네오디움 자석의 중심부 자기장 세기는 자 석의 위치에 따라 약간의 차이는 있으나 4800 5100 Gauss를 나타내었다. 방사선 조사 후 $15{ }^{\circ} \mathrm{C} / \mathrm{sec}$ 의 가온 율로 TLD의 글로우곡선을 얻은 결과 낮은 트랩의 열 형광 Peak는 $145{ }^{\circ} \mathrm{C}$ 근처에서 나타나고, 깊은 트랩의 열형광 peak는 $230{ }^{\circ} \mathrm{C}$ 근처에서 나타났다[Fig 3]. TLD-100의 자기장 노출과 비노출에 대한 결과에서 깊 은 트랩의 글로우 곡선은 자기장 노출의 유무에 관계 없이 큰 변화를 나타내지 않았으나 자기장 노출에 의
해 낮은 트랩의 열형광 peak는 Fig. 3의 (b)와 같이 감 소하는 것으로 나타났다.

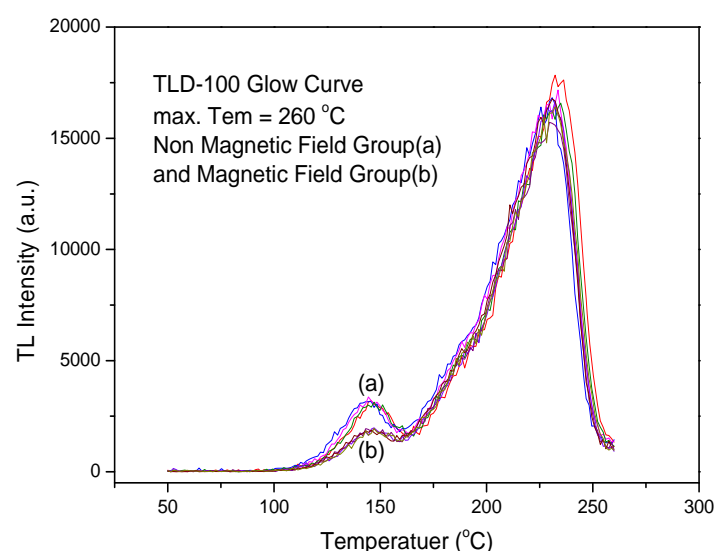

Fig. 3. Glow Curve of Non Magnetic Field and Magnetic Field Exposure.

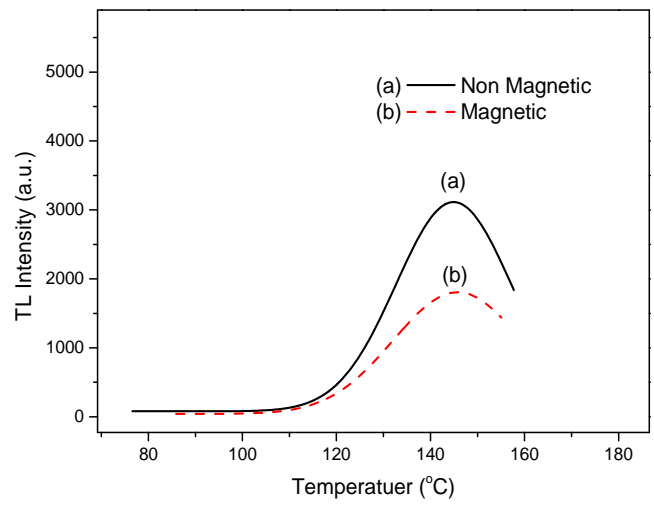

Fig. 4. Gaussian Fitting Graph.

각각의 글로우 곡선 peak는 금지대 내에 있는 trap들 의 정보를 가지고 있으므로, 각 trap에 대한 포획 매개 변수를 결정하기위해 본 연구에서는 자기장 노출에 의해 감소를 나타낸 낮은 트랩의 형광 peak만 Gaussian fitting을 이용하여 단일 glow curve로 분리한 후 Origin Program (Version 8.5)을 이용하여 글로우 곡선의 면적 과 활성화 에너지를 구하였다[Fig.4]. Fig.4에서 단일 글 로우 곡선으로부터 peak (a)의 면적은 $3.04 \times 103$ 이고 peak (b)의 면적은 $1.77 \times 103$ 으로 나타났다. 즉, 자기장 노출에 의하여 낮은 온도의 트랩 면적이 $42 \%$ 감소하 는 것으로 나타났다. 그리고 선량 평가에서도 자기장 에 노출되지 않은 4 개의 평균선량은 $2859 \mu \mathrm{Gy}$ 로 나타 났으며, 자기장에 노출된 4 개의 평균선량은 $2642 \mu \mathrm{Gy}$ 로 $7.6 \%$ 감소하는 것으로 나타났다. 추가로 자기장 노 
출 유무에 따른 2 개의 글로우 곡선을 peak shape법으 로 Chen의 공식을 이용하여 활성화 에너지는 구하였 으며, Fig. 4의 peak (a) 활성화 에너지는 $1.6 \mathrm{eV}$, peak (b) 활성화 에너지는 $1.5 \mathrm{eV}$ 나타났다.

\section{IV. 고 찰}

열형광은 $\mathrm{X}$ 선이나 $\mathrm{\gamma}$ 선, 하전입자, 자외선 등과 같은 방사선을 조사한 후 시료를 가열하면 시료로부터 흡 수된 에너지의 일부가 더 긴 파장의 빛으로 방출되는 것을 말한다. 즉, 온도에 대응하는 트랩에 전자들이 가 장 많이 갇혀 있다가 결국 탈출함으로서 최대의 열형 광 양을 방출하게 되므로 주 peak가 형성되는 것이다 ${ }^{[9]}$. 본 연구는 개인피폭선량계인 TLD-100의 자기장 노 출 유무에 따른 글로우 곡선과 방사선량을 획득하여 분석하였다. 자기장 노출에 의해 변화된 $145{ }^{\circ} \mathrm{C}$ 근처 의 낮은 트랩 peak는 Gaussian fitting을 통하여 peak의 면적, 활성화 에너지를 구하였다. 자기장이 TLD에 노 출이 되면 낮은 온도의 트랩 peak들이 감소하고 글로 우 곡선 전체를 방사선량으로 평가할 때 $7.6 \%$ 의 선량 감소를 나타내었다. 즉, 선량 평가에서는 2012년에 동 저자가 발표한 기존 연구와 같은 선량 감소의 결과를 나타내었다 ${ }^{[10]}$. 자기장 노출에 의하여 글로우 곡선의 트랩 위치는 변하지 않으나 낮은 온도의 트랩에 포획 된 전자가 자기장 노출로 인하여 이탈하는 것으로 판 단되어진다. 일반적으로 TLD-100에 진단용 X선을 조 사하면 글로우 곡선에서 $140{ }^{\circ} \mathrm{C}$ 근처의 peak를 확인할 수 있으며 이 peak의 활성화 에너지는 $1.4 \mathrm{eV}$ 정도를 나타낸다 ${ }^{[11]}$. 본 연구에서는 $145{ }^{\circ} \mathrm{C}$ 근처에서 peak가 나타나며, 이 peak의 활성화 에너지를 계산한 결과 $1.6 \mathrm{eV}$ 와 $1.5 \mathrm{eV}$ 로 나타나 기존 연구들과의 활성화 에 너지 비교에서는 비슷하게 나타났다.

\section{$\mathrm{V}$. 결 론}

자기장이 TLD의 글로우 곡선에 미치는 영향을 분 석한 결과 낮은 온도에서의 트랩 peak가 큰 변화를 보 였으며, 낮은 트랩에 포획된 전자는 자기장에 의해 포 획된 전자들이 가전자대로 이동하여 나타난 결과로 판단되어진다. PET-MRI 환경에서 개인피폭선량계로 $\mathrm{TLD}$ 를 사용할 경우 포획된 전자들의 이동으로 인하
여 방사선량이 감소하고 방사선작업종사자의 실제 피 폭선량보다 낮은 피폭선량 값을 나타낼 것이다. 그러 나 포획된 전자가 감소하여 글로우 곡선 peak의 강도 가 낮아지더라도 활성화 에너지에는 큰 영향을 미치 지 않으며, 추가적인 연구를 통하여 자기장 노출시간 과 자기장 세기에 따른 포획된 전자들의 분석과 TLD 물질의 종류에 따른 글로우 곡선 분석이 필요할 것으 로 사료된다.

\section{참고문헌}

[1] Wiedemann E and Schmidt GC, Ann. Phys. Chem, Neue Folge Vol. 54, pp. 604, 1895.

[2] Randall JT and Wilkins MHF, Proc. Roy. Soc. London, Vol. A184, pp. 347-390, 1945.

[3] Chen R and Kirsh Y, "Analysis of Thermally Stimulated Processes", Pregamon Press, Oxford, pp. 159, 1981.

[4] Kenneth S and Krane, "Introductory Nuclear Physics", John Wiley and Sons, Inc., pp. 192, 1988.

[5] Pradhan AS, "Radiation Protection Dosimetry", Vol. 13, pp. 153, 1981.

[6] Halperin A and Braner AA, Phys. Rev. Vol. 117, pp. 408, 1960.

[7] Grossweiner LI, J. Appl. Phys. Vol. 24, pp. 1306-1307, 1953.

[8] Lushchick CB, Sov. Phys. JETP. Vol. 3, pp.390-399, 1956.

[9] Kim CM, Seo MK, "A Study on the Fabrication and Physical Properties oF Ca2SiO4:La Thermoluminescent Phosphors", J. Korea Soc. Radiol. Vol. 4 No. 4, pp. 7, 2010.

[10] Je JY, Kang EB, "TLD Dose Variation of Magnetic Resonance Imaging Equipment", J. Korea Soc. Radiol. Vol. 6 No. 6, pp. 473-476, 2012.

[11] Ixquiac-Cabrera JM, Brandan ME et al., "Effect of Spectral Shap in the relative Efficiency of LiF:Mg,Ti Exposed to 20 keV Effective Energy X-ray" radiat meas. Vol. 46, pp. 389-395, 2011. 